\title{
A MERCANTILIZAÇÃO DA MORADIA E O PROGRAMA MINHA CASA, MINHA VIDA: DAS RELAÇÕES ENTRE ESTADO E AGENTES PRIVADOS À SEGREGAÇÃO SOCIOESPACIAL
}

\author{
THE MERCHANTABILITY OF THE HOUSING AND THE "MINHA CASA, MINHA \\ VIDA" PROGRAM: FROM THE RELATIONS BETWEEN STATE AND PRIVATE \\ AGENTS TO SOCIO-SPATIAL SEGREGATION
}

\section{LA MERCANTILIZACIÓN DE VIVIENDA Y EL "PROGRAMA MINHA CASA, MINHA VIDA": DE LAS RELACIONES ENTRE ESTADO Y AGENTES PRIVADOS A LA SEGREGACION SOCIOESPACIAL}

\begin{abstract}
Clarissa de Oliveira Gomes MARQues da CUNHA https://orcid.org/0000-0003-2567-141X / http://lattes.cnpq.br/6617245097291351 / marquesc2504@gmail.com Universidade de Pernambuco (UPE) Programa de Pós-Graduação em Direito da Faculdade Damas (PPGD-ARIC-FADIC)
\end{abstract} Recife, PE, Brasil.

ANNe Gabriele Alves Guimarães https://orcid.org/0000-0003-1950-2417 / http://lattes.cnpq.br/1604514253864700 / annegabrielebj@hotmail.com Universidade de Pernambuco (UPE) / Campus Arcoverde Arcoverde, PE, Brasil

\begin{abstract}
RESUMO
A pesquisa se propõe a analisar de que modo a mercantilização da terra e o uso crescente da habitação como ativo financeiro globalizado afetam o exercício do direito à moradia adequada. A partir de um tipo bibliográfico com viés descritivo, destaca-se o abandono de políticas públicas em que a habitação é considerada um bem social ou meio de distribuição de riqueza. A disciplina de mercado assume o protagonismo nas cidades. Nesta perspectiva, toma-se como base o Programa Minha Casa, Minha Vida e suas articulações entre agentes públicos e privados para contextualizar o processo de financeirização da moradia e sua relação com a crescente segregação socioespacial no Brasil. Constata-se, portanto, que o PMCMV vem exercendo um papel ativo na perpetuação da segregação em razão da renda e na reiteração da periferia enquanto lugar dos desvalidos nas cidades brasileiras.
\end{abstract}

Palavras-chave: Capitalismo; Mercantilização; Moradia; Segregação.

\section{ABSTRACT}

The research propounds to analyze how the merchantability of land and the increasing use of housing as a globalized financial asset affect the exercise of the right to adequate housing. From a bibliographic type with descriptive bias, it is worth noting the abandonment of public policies in which housing is considered a social good or means of wealth distribution. Market discipline takes center stage in cities. In this perspective, it is observed how the "Minha Casa, Minha Vida" Program and its articulations between public and private agents are used to contextualize the financialization process of housing and its relation with the growing socio-spatial segregation in Brazil. It's verified that, therefore, the "Minha Casa, Minha Vida" Program is exerting an active role into the segregation's perpetuation in the ratio of income and in the reiteration of the outskirts while place for the helpless in Brazilian cities.

Keywords: Capitalism; Merchantability; Housing; Segregation. 


\section{RESUMEN}

La presente investigación se propone analizar la mercantilización de territorios y viviendas como activos financieros globalizados afectan al derecho a las adecuadas viviendas. A partir de estudios bibliográficos con sesgos descriptivos se percibe y destaca el abandono de políticas públicas en que se considera la vivienda un bien social o medio de distribución de riqueza. El Mercado asume el protagonismo en las ciudades. En este eje se toma como base el Programa Social brasileño "Minha Casa, Minha Vida" y sus articulaciones entre agentes públicos y privados en el proceso de financiamiento de viviendas y su relación con la segregación socioespacial en Brasil. Se constata, por lo tanto, que el PMCMV viene ejerciendo un papel activo en la perpetuación de la segregación en razón de la renta y en la reiteración de la periferia como lugar de desvalidos en las ciudades brasileñas.

Palabras-clave: Capitalismo; Mercantilización; Vivienda; Segregación.

\section{SUMÁRIO}

INTRODUÇÃO; 1 A FINANCEIRIZAÇÃO DA MORADIA E SUAS CONSEQUÊNCIAS NEOLIBERAIS: A SAÍDA PROGRESSIVA DO GOVERNO DO SETOR HABITACIONAL; 2 O PROGRAMA MINHA CASA, MINHA VIDA FRENTE À FINANCEIRIZAÇÃO DA MORADIA NO BRASIL; 3 A SEGREGAÇÃO SOCIOESPACIAL EM TEMPOS DE FINANCEIRIZAÇÃO: A LUTA DA POPULAÇÃO DE BAIXA RENDA PELA INTEGRAÇÃO AO TECIDO URBANO NO CONTEXTO DO PMCMV; CONCLUSÃO; REFERÊNCIAS.

\section{INTRODUÇÃO}

Pensar a cidade revela a sensibilidade humana acerca do lugar onde se vive. Para além de um mero aglomerado de pessoas, o conceito associado ao urbano também se desdobra em memórias, registros e materializações. Alçado à categoria de direito humano, o direito à cidade é a tentativa genuína de transformar o humano por meio das mudanças na comunidade. É o exercício de um direito comum e difuso.

A urbanização, entretanto, é vista como um fenômeno de classes, responsável por mobilizar o excedente capitalista ${ }^{1}$. Neste sentido, a história das primeiras cidades exsurge da concentração social e demográfica do produto excedente, verdadeiro terreno lucrativo da política do capitalismo. Estes fatores fomentam o círculo vicioso acumulador de riquezas nas mãos de poucos.

Da Paris do urbanista Haussmann à suburbanização dos EUA, têm-se projetos de embelezamento e higienização que retiraram o direito à cidade de muitos. Até os dias de hoje, percebe-se que a urbanização continua a ter forte viés corporativista-imobiliário. Esse último, a partir da primeira década do século XXI, desemboca em um longo processo de desconstrução da habitação, transformando-a em mercadoria ou, mais ainda, em ativo financeiro globalizado.

\footnotetext{
${ }^{1}$ HARVEY, David. O direito à cidade. Lutas Sociais, São Paulo, n.29, p.73-89, jul./dez. 2012.
} 
ISSN 1981-3694

(DOI): $10.5902 / 1981369431760$

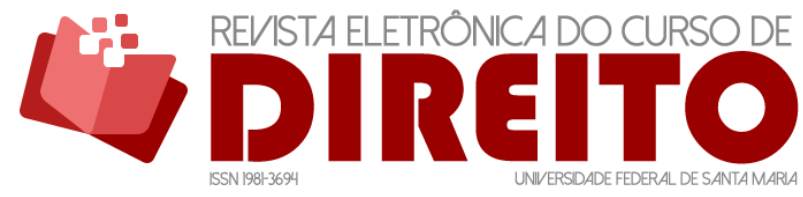

A MERCANTILIZAÇÃO DA MORADIA E O PROGRAMA MINHA CASA MINHA VIDA: DAS RELAÇÕES ENTRE ESTADO E AGENTES PRIVADOS À SEGREGAÇÃO SOCIOESPACIAL

Clarissa de Oliveira Gomes MARQues da CUNHA ANNE GABRIELE ALVES GUIMARÃES

A economia política da habitação passa a fazer parte da era da hegemonia das finanças e do domínio crescente da extração de renda sobre o capital produtivo. 0 processo de financeirização ou mercantilização da moradia envolve atores, mercados e práticas financeiras, modificando as economias, os Estados e, principalmente, os grupos familiares ${ }^{2}$.

A mudança no sentido e no papel econômico da habitação, alicerçada na hegemonia do livre mercado, também está relacionada, no final da década de 70 , às políticas de desmanche dos componentes institucionais básicos que compunham o Estado de bem-estar social. 0 que existe, na verdade, é um desmonte das políticas de habitação pública e social e a transmutação da casa em ativo financeiro ${ }^{3}$. A cidade é, portanto, reajustada de acordo com pressupostos neoliberais.

Dá-se, então, a saída progressiva do governo do setor de habitação - se o mercado pode atuar, o Estado sai de cena pretensiosamente. Esta problemática referente à financeirização da terra afeta profundamente o exercício do direito à moradia adequada não apenas no Brasil, mas ao redor do mundo. A habitação perde sentido sociocultural, deixando de ser um bem social ou meio de distribuição de riqueza.

Nesta economia política centrada em excedentes e especulações, a moradia torna-se um meio de acesso a valores econômicos. Por meio dela, gera-se uma expectativa de aumento do preço dos imóveis em um futuro próximo.

A tomada do setor habitacional pelo setor financeiro, no Brasil, atinge seu ápice com o Programa Minha Casa, Minha Vida (PMCMV), lançado em 2009, responsável por articular agentes públicos e privados, beneficiar o setor imobiliário e acomodar atores e interesses na busca pelo capital político. A forma estrutural do PMCMV foi idealizada de maneira que a iniciativa privada orientasse a pauta desta política habitacional ${ }^{4}$.

O protagonismo do mercado privado, típico do referido projeto/PMCMV, acabou por proporcionar a criação de conjuntos habitacionais localizados em áreas afastadas, ratificando um padrão histórico de segregação socioespacial dos mais vulneráveis ${ }^{5}$. 0 título de propriedade torna-se, então, mais importante que o direito à cidade e à moradia digna.

\footnotetext{
2 ROLNIK, Raquel. Guerra dos lugares: a colonização da terra e da moradia na era das finanças. São Paulo: Boitempo, 2015, p. 28.

${ }^{3}$ ROLNIK, Raquel. Guerra dos lugares: a colonização da terra e da moradia na era das finanças. São Paulo: Boitempo, 2015, p. 30.

${ }^{4}$ ROLNIK, Raquel. Guerra dos lugares: a colonização da terra e da moradia na era das finanças. São Paulo: Boitempo, 2015, p. 310.

${ }^{5}$ ROLNIK, Raquel. Guerra dos lugares: a colonização da terra e da moradia na era das finanças. São Paulo: Boitempo, 2015, p. 312.
} 
A partir de um tipo bibliográfico com viés descritivo e método de abordagem indutivo, o presente trabalho discute de que modo a mercantilização da terra e o uso crescente da habitação como ativo financeiro globalizado afetam o exercício do direito à moradia adequada.

Para tanto, encontra-se dividido em três seções, cujos objetivos são: discorrer sobre o processo de financeirização da moradia e a saída progressiva do governo do setor habitacional, analisar o PMCMV e suas articulações entre agentes públicos e privados no capitalismo e, por fim, analisar também se a estrutura pensada para este programa fomentou a segregação socioespacial da população de baixa renda. Autores como Raquel Rolnik, David Harvey, Noam Chomsky e Milton Santos servirão de fundamentação teórica.

Destaca-se, ainda conforme observação metodológica, que a utilização das terminologias “moradia” e "habitação" no presente trabalho não segue os postulados do direito civil, para o qual o direito à moradia é um bem jurídico pertencente à pessoa e o direito de habitação, instrumentalização do direito à moradia, podendo ser gratuito ou oneroso, com caráter de direito real ou de direito pessoal.

Sob o aspecto do direito civil, tal distinção possui finalidade prática: a perda ou suspensão do direito de habitação deve observar a tutela jurídica da moradia ${ }^{6}$. Entretanto, a pesquisa ora apresentada adota o entendimento dos teóricos acima listados, e que serviram de fundamentação teórica, no sentido de não realizar diferenciação entre as expressões "moradia" e "habitação" uma vez que a problemática enfrentada não foi acompanhada de uma investigação com marcos próprios do direito civil.

\section{A FINANCEIRIZAÇÃO DA MORADIA E SUAS CONSEQUÊNCIAS NEOLIBERAIS: A SAÍDA PROGRESSIVA DO GOVERNO DO SETOR HABITACIONAL}

A noção de cidade como local de circulação de mercadorias coincide com seu próprio viés mercadológico, tendo em vista que os espaços urbanos têm preços em função de atributos físicos (declividade do terreno ou qualidade da construção) e locacionais (acesso a equipamentos

\footnotetext{
${ }^{6}$ NUNES DE SOUZA, Sérgio Iglesias. Direito à moradia e de habitação: análise comparativa e seu aspecto teórico e prático com os direitos da personalidade. 3. ed. São Paulo: Thomson Reuters Revista dos Tribunais, 2013.
} 
ISSN 1981-3694

(DOI): $10.5902 / 1981369431760$

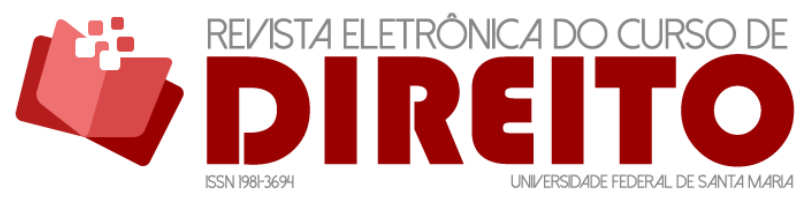

A MERCANTILIZAČ̃̃ DA MORADIA E O PROGRAMA MINHA CASA MINHA VIDA: DAS RELAÇÕES ENTRE ESTADO E AGENTES PRIVADOS À SEGREGAÇÃO SOCIOESPACIAL

Clarissa de Oliveira Gomes MARQUES da CUNHA ANNE GABRIELE ALVES GUIMARÃES

de serviços e negócios ou proximidade a áreas nobres) ${ }^{7}$. A cidade é, portanto, mercadoria e circula à semelhança de veículos e cargas.

Por outro lado, a chamada especulação imobiliária, alimentada pelo capital financeiro, gera terrenos vazios e localizações retidas pelos proprietários, na expectativa de futuras valorizações, provocando "vazios urbanos". O que se almeja, a partir destes terrenos de engorda, na contramão da função social, é capturar investimentos em infraestrutura ou grandes obras na região ${ }^{8}$.

Ainda do ponto de vista econômico, o capital aplicado principalmente em setores e ativos habitacionais abre frente de investimentos, sendo peça primordial no jogo de poder da cidade. Este cenário é propício ao desembocar do fenômeno intitulado de financeirização/mercantilização da terra, contribuindo para agravar a situação de instabilidade da moradia.

O processo de financeirização ou mercantilização da habitação envolve atores, mercados e práticas financeiras, modificando as economias, os Estados e, principalmente, os grupos familiares. Por meio dele, as políticas habitacionais e urbanas perdem seu caráter de distribuição de riqueza para se transformarem em mecanismos de extração de renda e acumulação de capital, típicos do paradigma neoliberal ${ }^{9}$.

O neoliberalismo, segundo Noam Chomsky, consiste em um conjunto de processos econômicos, políticos e culturais que permitem a um pequeno número de interesses particulares controlar a maior parte possível da vida social. As consequências dessas políticas são as mesmas em todos os lugares: crescimento da desigualdade econômica, aumento marcante da pobreza absoluta entre as nações e uma bonança sem precedente para os ricos.

Sob a ótica neoliberal, os problemas de produção e distribuição de recursos devem ser resolvidos pelas forças do mercado. “Resumidamente, as suas regras básicas são: liberalização do mercado e do sistema financeiro, fixação dos preços pelo mercado ('ajuste de preços'), fim da inflação ('estabilidade macroeconômica') e privatização"10. Esse modelo econômico de anseios globais, propulsor da globalização econômica e de um crescimento sem freios, promove

\footnotetext{
${ }^{7}$ ROLNIK, Raquel. O que é cidade? São Paulo: Brasiliense, 1995, p. 69.

${ }^{8}$ ROLNIK, Raquel. O que é cidade? São Paulo: Brasiliense, 1995, p. 70.

9 ROLNIK, Raquel. Guerra dos lugares: a colonização da terra e da moradia na era das finanças. São Paulo: Boitempo, 2015.

${ }^{10}$ CHOMSKY, Noam. O lucro ou as pessoas: neoliberalismo e ordem global. Trad. Pedro Jorgensen Jr. Rio de Janeiro: Bertrand Brasil, 2002, p. 22.
} 
ISSN 1981-3694

(DOI): $10.5902 / 1981369431760$

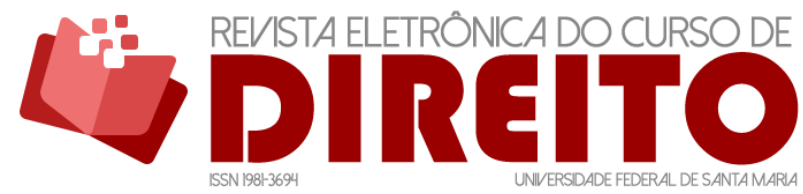

A MERCANTILIZAÇÃO DA MORADIA E O PROGRAMA MINHA CASA MINHA VIDA: DAS RELAÇÕES ENTRE ESTADO E AGENTES PRIVADOS À SEGREGAÇÃO SOCIOESPACIAL

Clarissa de Oliveira Gomes MARQues da CUNHA ANNE GABRIELE ALVES GUIMARÃES

atividades e ações locais que afetam a todos, face à interdependência ecológica no espaço territorial global ${ }^{11}$.

Uma ressalva deve ser feita: embora se fale em hegemonia do mercado imobiliário, deve-se atentar para o fato de que ela não é nova. Nova é a força da financeirização, detentora de controle sobre as cidades e responsável pela submissão da política urbana. Dentro dessa lógica, o mercado tem a obrigação de produzir, o que implica em mecanismos de desconstrução da habitação, transformando-a em ativo financeiro globalizado. Deste modo, o sistema financeiro habitacional, ao representar o excedente capitalista, movimenta fluxos de recursos internacionais.

Nesse sentido, o boom imobiliário depende da criação de instituições e mecanismos financeiros que permitam organizar o crédito $^{12}$. 0 mercado de hipotecas, neste ínterim, foi um dos veículos importantes por conectar os sistemas domésticos de moradia aos mercados globais. Ainda exerceram papel de influência os empréstimos interbancários e os esquemas de microfinanciamento, a título de exemplo.

Destaca-se ainda que a financeirização da terra se reveste da força ideológica da "casa própria" e da expansão do crédito juntamente com a inclusão de consumidores de média e baixa renda nos circuitos financeiros. A dinâmica da cidade constata, a partir de então, a tomada do setor habitacional pelas finanças.

A mudança no sentido e no papel econômico da moradia, alicerçada na hegemonia do livre mercado, também está relacionada, no final da década de 70 , às políticas de desmanche dos componentes institucionais básicos que compunham o Estado de bem-estar social, oriundas da crise fiscal. O que existe, na verdade, é um desmonte das políticas de habitação pública e social, a desestabilização da segurança da posse e a transmutação da casa em ativo financeiro. 0 espaço urbano é, então, reajustado de acordo com pressupostos neoliberais ${ }^{13}$.

Uma redução significativa na construção de moradia adequada e pública para os grupos vulneráveis aconteceu simultaneamente à diminuição dos orçamentos governamentais

\footnotetext{
${ }^{11}$ CUNHA, Clarissa de Oliveira Gomes Marques da; PORTO, Simone Peixoto Ferreira. A negação da natureza e o projeto de desenvolvimento: a busca por uma racionalidade ambientalmente sustentável. Revista Eletrônica do Curso de Direito da UFSM, Santa Maria, RS, v. 12, n. 3, p. 910-936, dez. 2017. ISSN 19813694. Disponível em: https://periodicos.ufsm.br/revistadireito/article/view/27173. Acesso em: $15 \mathrm{fev}$. 2019. doi: http://dx.doi.org/10.5902/1981369427173.

12 HARVEY, David. Cidades rebeldes: do direito à cidade à revolução urbana. São Paulo: Martins Fontes, 2014.

13 ROLNIK, Raquel. Guerra dos lugares: a colonização da terra e da moradia na era das finanças. São Paulo: Boitempo, 2015, p. 32.
} 
destinados à habitação social. Neste período, houve uma crescente estigmatização da habitação pública, que passou a ser associada à pobreza e marginalidade.

A saída progressiva do governo do setor de habitação está alicerçada sob a perspectiva neoliberal da necessidade de redução do gasto público e da retirada do Estado de áreas em que o mercado pode atuar.

A redução da intervenção do Estado em campos considerados como de domínio do mercado tem dado suporte aos processos de privatização dos serviços básicos e a promoção do consumo como meio de acesso a direitos ${ }^{14}$. Analisando os atores desta transformação urbana:

Mais do que a eliminação da habitação social da paisagem econômica e social de suas cidades, ocorreu uma profunda transformação de seu sentido sociocultural e político. Claramente, os atores envolvidos na produção e no consumo da habitação social perdem poder em relação à ascensão não apenas dos proprietários (homeowners), mas, sobretudo, dos incorporadores (developers) e intermediários financeiros ${ }^{15}$.

A habitação perde sentido sociocultural ao deixar de ser um bem social ou meio de distribuição de riqueza, tornando-se um meio de acesso a valores econômicos. Por meio dela e de acordo com a economia política centrada em especulação, gera-se uma expectativa de aumento do preço dos imóveis em um futuro próximo.

A mercantilização da terra, deste modo, afeta a estruturação dos contextos urbanos, uma vez que, segundo já analisado, os governos renunciam ao papel de provedores da habitação de custo acessível e tornam-se meros facilitadores. Neste sentido, destaca-se:

O orçamento público e os fundos financeiros do Estado deixaram de ser responsáveis pela universalização das políticas públicas, limitando-se ao atendimento de demandas focalizadas e ao fomento das economias de mercado. Alguns autores afirmam mesmo que o orcamento fiscal do Estado passa a ser direcionado também para garantir a rentabilidade de aplicações financeiras de investidores privados ${ }^{16}$.

A função principal do Estado capitalista e pós-colonial é ratificar relações sociais dominantes, o que inclui aproveitar os momentos de conflitos, como a crise fiscal da década de

\footnotetext{
${ }^{14}$ ARAGÃO, Thêmis Amorim. A financeirização da moradia no Brasil: a cidade como direito ou mercadoria? Le Monde Diplomatique. Brasil, web, 26 ago. 2016.

${ }^{15}$ ROLNIK, Raquel. Guerra dos lugares: a colonização da terra e da moradia na era das finanças. São Paulo: Boitempo, 2015, p. 74.

${ }^{16}$ ROYER, Luciana de O. Financeirização da política habitacional: limites e perspectivas. 2009. $193 \mathrm{f}$. Tese (Doutorado em Arquitetura e Urbanismo) - Programa de Pós-Graduação em Arquitetura e Urbanismo, Universidade de São Paulo, São Paulo. 2009, p. 13-14.
} 
1970, para a reprodução socioeconômica, cultural e política ${ }^{17}$. Assim, na fase de expansão material do sistema capitalista (século XX), o fundo público constituía a fonte mais importante de financiamento da política habitacional. Com a crise fiscal, os fundos administrados pelos governos logo se tornaram insuficientes para atender as necessidades básicas da classe trabalhadora, fazendo com que o mercado passasse a atuar com protagonismo.

Neste imperativo superposto de continuar o processo de acumulação é que "o Estado não é um ator neutro que atua independentemente da sociedade, formulando a vontade geral $e$ solucionando problemas"18. Acredita-se, portanto, que as confluências entre aparato estatal, mercado imobiliário e capital financeiro inserem-se na perspectiva de manutenção, agora mais acentuada, da estrutura colonial capitalista. Tais confluências são, pois, articulações de interesses políticos e econômicos, através das quais o Estado legitima os interesses do capital.

Em suma, as profundas modificações do padrão de acumulação de riquezas somadas à disseminação das finanças enquanto base da organização do patrimônio em escala mundial “impuseram uma nova racionalidade ao desenho institucional das políticas públicas, tanto nos países do centro quanto nos países subdesenvolvidos" ${ }^{19}$. A apropriação do excedente capitalista resultou em uma nova maneira de tratar os direitos e ofertar bens e serviços públicos. Seguindo esta tendência, a política habitacional, política ligada à efetivação do direito à moradia, aderiu ao movimento, migrando para a lógica seletiva dos mercados.

Esta política habitacional de mercado é explicitada, de maneira indireta, por Harvey, quando contextualiza a constante luta capitalista em buscar meios de produção e terreno lucrativo para investir o que se convencionou chamar de muralha de dinheiro (wall of money):

A necessidade perpétua de encontrar terreno lucrativo para a produção e absorção de excedente de capital molda a política do capitalismo e, também, confronta os capitalistas com várias barreiras à contínua e problemática livre expansão. Se o trabalho é escasso e o salário é alto, o trabalho existente deve ser disciplinado - o desemprego tecnologicamente induzido e a investida contra o poder organizado da classe trabalhadora são os principais métodos - ou nova força de trabalho deve ser encontrada através da imigração, da exportação de capital ou da proletarização de elementos até então independentes da

\footnotetext{
${ }^{17}$ BRAND, Ulrich. Estado e políticas públicas: sobre os processos de transformação. In: LANG, Miriam et al. (Org.). Descolonizar o imaginário. Debates sobre pós-extrativismo e alternativas ao desenvolvimento. São Paulo: Elefante, 2016, p. 123-137.

${ }^{18}$ BRAND, Ulrich. Estado e políticas públicas: sobre os processos de transformação. In: LANG, Miriam et al. (Org.). Descolonizar o imaginário. Debates sobre pós-extrativismo e alternativas ao desenvolvimento. São Paulo: Elefante, 2016, p. 131.

19 ROYER, Luciana de O. Financeirização da política habitacional: limites e perspectivas. 2009. 193 f. Tese (Doutorado em Arquitetura e Urbanismo) - Programa de Pós-Graduação em Arquitetura e Urbanismo, Universidade de São Paulo, São Paulo. 2009, p. 13.
} 
população. Os capitalistas devem, também, descobrir novos meios de produção, em geral, e recursos naturais, em particular, que aumentem a pressão sobre o ambiente natural para revelar matéria prima indispensável e absorver os resíduos inevitáveis. Eles precisam explorar terrenos para extração de matéria prima, objetivo frequente dos empreendimentos imperialistas neocoloniais ${ }^{20}$.

Assim como a urbanização é um fenômeno de classe, o capitalismo precisa do excedente para obter mais-valia, que, por sua vez, deve ser reinvestida. A abertura de frentes de expansão para um capital imobiliário e financeirizado, ampliado exponencialmente nas cidades, reflete este processo de aplicação de ativos no mercado global especulativo.

Não há preocupação com os mais vulneráveis nem com formas de organização urbana socialmente mais justas. A discussão, inserida no cenário de hegemonia capitalista, perpassa, sim, qual é o melhor projeto ou sua rentabilidade para o sistema imobiliário.

Pelos ditames neoliberais da financeirização da terra, a cidade é colonizada e o direito dos moradores torna-se irrelevante. Sendo os espaços urbanos apropriados e precificados com base no valor de mercado, perde-se a oportunidade de que sejam utilizados conforme o interesse público de moradia.

\section{O PROGRAMA MINHA CASA, MINHA VIDA E A FINANCEIRIZAÇÃO DA MORADIA NO BRASIL}

O processo de financeirização desconstrói a moradia enquanto direito autônomo e passível de concretização, responsável por integrar as pessoas ao território da cidade. $\mathrm{Na}$ verdade, por meio deste fenômeno, já explicado na seção acima, há o afastamento do Estado do setor de habitação, cujo papel é tão somente facilitar o desenvolvimento de grandes projetos imobiliários.

Entretanto, para os fins deste trabalho, a discussão "está voltada à promoção do direito à moradia a partir da atuação estatal, mediante a definição e a implementação de políticas públicas habitacionais"21. 0 estudo do Programa Minha Casa, Minha Vida (PMCMV) torna-se relevante nesta empreitada, pois, apesar de ser o modelo de habitação federal vigente, é muito mais uma política econômica com grandes pactos políticos.

\footnotetext{
${ }^{20}$ HARVEY, David. O direito à cidade. Lutas Sociais, São Paulo, n.29, p.74, jul./dez. 2012.

${ }^{21}$ MASTRODI, Josué; ZACCARA, Suzana Maria Loureiro Silveira. O que é o objeto "moradia" do Programa Minha Casa, Minha Vida? Revista de Direito da Cidade, Rio de Janeiro, vol. 8, n.3, p. 860, 2016.
} 
De antemão, ao examinar a conjuntura de provisão da habitação brasileira ao longo dos anos, percebe-se que sua dinâmica permeia a reprodução institucionalizada de títulos de propriedade. Desde o BNH (1964-1985), em que já se tinha a ideia de casa própria e individual, até o PMCMV, a produção de conjuntos habitacionais aparece como modelo e única alternativa possível. Nesta perspectiva:

Desde os anos 1990 vêm se constituindo, no Brasil, mecanismos jurídicos e institucionais que prepararam o terreno para a ampliação e a consolidação da produção privada de moradias, inclusive para uma faixa de renda familiar que anteriormente não era atendida pelo mercado formal promovido por grandes empresas. Sem grande alarde, o mercado imobiliário passou a ocupar a posição de ator central na política brasileira recente de habitação ${ }^{22}$.

Tal cenário "máquina de produção de casas" é entendido quando o direito à moradia, objeto da pesquisa, perde sua autonomia em relação ao direito de propriedade. A moradia não possui autonomia suficiente frente àquele instituto. Não se consegue proteger a posse pelo fato de existir alguém com o animus de ser morador, porque, erigidos sob a ótica liberal-privatista, visa-se antes a proteção da propriedade (imóvel) e seu respectivo título ${ }^{23}$. O PMCMV, deste modo, promove a moradia a partir da propriedade imobiliária.

Assim, a estrutura deste programa, lançado pelo Governo Federal em parceria com Estados, Municípios e $\mathrm{CEF}^{24}$ ao ser instituído pela Lei n. 11.977 de 07 de julho de $2009^{25}$, concentra outros subprogramas voltados à redução do déficit habitacional brasileiro através da concessão de incentivos para aquisição da casa própria. Foi formulado para atender a três faixas de renda distintas, cujas metas, subvenções e mecanismos de contratação variam ${ }^{26}$. A Faixa 1 é

22 SHIMBO, Lúcia Zanin. Habitação social, habitação de mercado: a confluência entre estado, empresas construtoras e capital financeiro. 2010. $361 \mathrm{f}$. Tese (Doutorado em Arquitetura e Urbanismo) - Programa de Pós-Graduação em Arquitetura e Urbanismo, Escola de Engenharia de São Carlos da Universidade de São Paulo, São Paulo. 2010, p. 23.

${ }^{23}$ MASTRODI, Josué; ZACCARA, Suzana Maria Loureiro Silveira. O que é o objeto "moradia" do Programa Minha Casa, Minha Vida? Revista de Direito da Cidade, Rio de Janeiro, vol. 8, n.3, p. 859-885, 2016.

${ }^{24}$ A CEF é o agente operacional e financeiro do PMCMV, que é gerido pelo Ministério das Cidades, utilizando recursos do Fundo de Desenvolvimento Social (FDS), Fundo de Garantia por Tempo de Serviço (FGTS), Fundo de Arrendamento Residencial (FAR), do Banco Nacional de Desenvolvimento Econômico e Social (BNDES) e do Fundo Garantidor da Habitação Popular (FGHab). Foi incluído no Programa de Aceleração do Crescimento 2 (PAC 2), em 2010, situado como um de seus eixos.

${ }^{25}$ A Lei $n$. 11.977, que instituiu o PMCMV, decorreu da MP n ${ }^{\circ} 459 / 2009$. Posteriormente, o programa teve seu texto legislativo alterado pelas seguintes leis: em 2010, a MP n 514/2010 deu origem à Lei n. 12.424, de 2011 e, pouco mais de um ano após a edição desta última lei, houve nova retificação da lei instituidora do PMCMV, pela MP n 570/2012, convertida 12.722, em 2012.

26 ROLNIK, Raquel et al. O Programa Minha Casa Minha Vida nas regiões metropolitanas de São Paulo e Campinas: aspectos socioespaciais e segregação. Cadernos Metrópole, São Paulo, v. 17, n. 33, p. 127-154, maio 2015. 
destinada às famílias com renda mensal de até $\mathrm{R} \$ 1.600,00$; a Faixa 2 para famílias que possuam renda mensal entre $R \$ 1.600,00$ e $R \$ 3.100,00$; e a Faixa 3 para famílias com renda mensal entre $\mathrm{R} \$ 3.100,00$ e $\mathrm{R} \$ 5.000,00^{27}$.

Cabe adiantar, desde já, que nosso objetivo é apontar os elementos-chave que fazem desta política uma canalizadora da mercantilização da terra e de capital político. Para tanto, busca-se problematizar dinâmicas de formulação do PMCMV frente à financeirização da moradia e suas articulações entre agentes públicos e privados no capitalismo. Conforme visto, além de conferir moradias pela entrega de propriedades imobiliárias, desvirtuando aquele direito de sua função autônoma na teoria constitucional, o PMCMV foi:

Explicitamente pensado enquanto estratégia de inspiração neokeynesiana para mitigar os efeitos da crise econômica mundial de 2008 [...] transcende a questão habitacional e insere-se num projeto político mais amplo, que tem na indústria da construção civil elemento-chave para dinamização da economia e o consumo enquanto principal mecanismo de inclusão social ${ }^{28}$.

O contexto em que se insere este programa revela o intuito de promover o aquecimento da economia estimulando o setor de construção civil. Ora, este segmento geralmente mobiliza mão-de-obra de baixa qualificação e é considerado um instrumento de políticas econômicas anticíclicas em momentos de recessão ${ }^{29}$.

A estratégia de viabilizar a produção de um grande número de moradias em curto espaço de tempo influenciou não somente a forma de inserção dos empreendimentos e sua qualidade urbanística como também patrocinou a conjuntura específica do setor imobiliário. 0 processo de financeirização da moradia no Brasil solidificou-se quando, para além de uma política habitacional, “o PMCMV foi também uma saída encontrada para evitar a falência generalizada de empresas de grande porte no setor imobiliário, mantendo a oferta de crédito no patamar necessário para que o setor pudesse manter suas atividades em ritmo acelerado" 30 .

\footnotetext{
${ }^{27}$ No início do programa, as faixas eram definidas em função do salário mínimo, de modo que a Faixa 1 destinava-se ao atendimento de famílias com renda mensal entre 0 e 3 s.m.; a Faixa 2, entre 3 e 6 s.m.; e a Faixa 3, entre 6 e 10 s.m. A partir de 2011, passou-se a definir as faixas com base em valores nominais.

28 CARDOSO, Adauto Lúcio; JAENISCH, Samuel Thomas. Nova política, velhos desafios: problematizações sobre a implementação do programa Minha Casa Minha Vida na região metropolitana do Rio de Janeiro. Emetropolis: Revista eletrônica de Estudos Urbanos e Regionais, v. 5, p. 7, 2014.

29 ROLNIK, Raquel et al. O Programa Minha Casa Minha Vida nas regiões metropolitanas de São Paulo e Campinas: aspectos socioespaciais e segregação. Cadernos Metrópole, São Paulo, v. 17, n. 33, p. 127-154, maio 2015.

30 ROLNIK, Raquel et al. O Programa Minha Casa Minha Vida nas regiões metropolitanas de São Paulo e Campinas: aspectos socioespaciais e segregação. Cadernos Metrópole, São Paulo, v. 17, n. 33, p. 131, maio 2015.
} 
A MERCANTILIZAÇÃO DA MORADIA E O PROGRAMA MINHA CASA, MINHA VIDA: DAS RELAÇÕES ENTRE ESTADO E AGENTES PRIVADOS À SEGREGAÇÃO SOCIOESPACIAL

Clarissa de Oliveira Gomes MARQues da CUNHA ANNE GABRIELE ALVES GUIMARÃES

Estas empresas, anos antes da recessão econômica em 2008, haviam aberto capital na bolsa de valores, formando verdadeiros bancos de terra. A mudança no cenário das finanças globais gerou perspectivas reais de quebra no setor. Para dar vazão ao estoque de capital imobilizado, vulgo excedente, o programa foi a saída de que precisavam. Entende-se a intensa participação de representantes da classe empresarial na formulação deste pacote.

Diante do exposto, constata-se um modelo de inclusão pelo consumo, em que a moradia é transmutada em mercadoria. Modelo este satisfatório aos detentores dos meios de produção determinantes do mercado (construtoras, incorporadoras e bancos).

O programa, portanto, foi sistematizado em função da iniciativa privada. Isto porque todas as questões ligadas ao direito social em tese estão submetidas ao contexto econômico, inclusive de artimanhas empresariais sedentas por lucro e produtividade. Para esclarecer as relações promíscuas entre agentes públicos e privados:

O modelo adotado pelo MCMV coloca a iniciativa privada como agente promotor da política, deslocando os interesses envolvidos na produção habitacional para âmbitos nos quais questões de caráter qualitativo associadas à dimensão social da moradia são subordinadas a questões econômicas, seja no sentido do impacto quantitativo do programa, seja através das estratégias empresariais que buscam ampliar ao máximo a taxa de lucro e a produtividade. No desenho institucional adotado pelo programa, quem decide onde o empreendimento será construído, a faixa de renda dos beneficiários e as características construtivas dos imóveis são as empresas incorporadoras, restando às administrações municipais (ou mesmo à sociedade civil) um papel coadjuvante neste processo ${ }^{31}$.

Os instrumentos da política habitacional acabam por deixar o Estado em segundo plano. Pelas condições já analisadas, a posição de coadjuvante estatal é feita pretensiosamente. Considera-se, portanto, o aparato estatal como um conjunto heterogêneo, uma condensação material de relações de força específicas, ou ainda, um ator não neutro ${ }^{32}$.

Ainda que não seja protagonista tanto quanto os atores do mercado privado de habitação, este Estado, na formulação e implantação do pacote MCMV, deu a possibilidade de financiamento habitacional a pessoas antes excluídas de programas de aquisição da propriedade (mercado formal de imóveis), jogando de dois lados: garantindo às incorporadoras demanda para

31 CARDOSO, Adauto Lúcio; JAENISCH, Samuel Thomas. Nova política, velhos desafios: problematizações sobre a implementação do programa Minha Casa Minha Vida na região metropolitana do Rio de Janeiro. Emetropolis: Revista eletrônica de Estudos Urbanos e Regionais, v. 5, p. 7, 2014.

32 BRAND, Ulrich. Estado e políticas públicas: sobre os processos de transformação. In: LANG, Miriam et al. (Org.). Descolonizar o imaginário. Debates sobre pós-extrativismo e alternativas ao desenvolvimento. São Paulo: Elefante, 2016, p. 123-137. 
ISSN 1981-3694

(DOI): $10.5902 / 1981369431760$

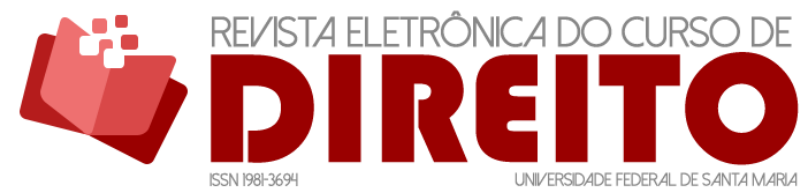

A MERCANTILIZAÇÃO DA MORADIA E O PROGRAMA MINHA CASA, MINHA VIDA: DAS RELAÇÕES ENTRE ESTADO E AGENTES PRIVADOS À SEGREGAÇÃO SOCIOESPACIAL

CLARISSA DE OliVEIRA GOMES MARQUES DA CUNHA ANNE GABRIELE ALVES GUIMARÃES

produção e garantindo capital político por estar supostamente combatendo déficits habitacionais.

O volume de recursos aplicados pelo programa dinamizou a economia, reestruturou os mercados imobiliários nacionais e criou um novo nicho de consumidores em potencial. Entretanto, "prioriza a construção de novas moradias em detrimento da compra das já existentes"33. É o círculo vicioso da financeirização e do excedente capitalista, sempre em busca de terreno lucrativo. Afinal, a característica do programa requer imóveis novos e não a mera compra e venda de unidades habitacionais já construídas.

Aproveitar os imóveis usados e desocupados, muitas vezes dotados de infraestrutura básica, poderia ser uma alternativa à construção de novas habitações, tendo em vista que as edificações vazias configuram um peso para a sociedade, principalmente quanto à inadimplência de impostos. A readaptação destes imóveis se utilizaria da infraestrutura urbana completa e da localização privilegiada das cidades, o que beneficiaria as famílias de baixa renda ${ }^{34}$.

A postura crítica em relação ao Minha Casa, Minha Vida, entretanto, não retira o fato de que, pela primeira vez na história de políticas habitacionais brasileiras, famílias com renda mensal inferior a três salários mínimos estão sendo contempladas, apesar da baixa qualidade arquitetônica dos empreendimentos e das dificuldades quanto à mudança para o novo endereço. Não se nega, neste sentido, que tal política é uma possibilidade tangível de melhora objetiva das condições de moradia, seja para escapar de áreas de risco, da violência urbana ou de situações de coabitação. Sem falar naqueles que aderem ao MCMV para obter uma garantia legal definitiva da posse do imóvel ou mesmo atraídos pelo desejo de consumir o produto imobiliário ${ }^{35}$.

O que merece desaprovação, portanto, é o paradigma neoliberal no qual se desenvolveu seu funcionamento e normatização, sobretudo por apostar na centralidade do setor empresarial como agente promotor, num contexto de baixa capacidade regulatória por parte do Poder Público e um controle social praticamente nulo.

$\mathrm{Na}$ conjuntura nacional, com o MCMV, a moradia deixa de ser um direito autônomo e passa a ser ativo financeiro, condicionando sua dimensão social à subordinação aos ditames

\footnotetext{
${ }^{33}$ MONTEIRO, Adriana Roseno; VERAS, Antonio Tolrino de Rezende. O Programa Minha Casa, Minha Vida e a produção do espaço urbano na cidade de Boa Vista - RR. Revista de Direito da Cidade, Rio de Janeiro, vol. 7, n. 3, p.1182, 2015.

${ }^{34}$ CORRÊA, Geovana de Medeiros. A habitação social em foco: uma abordagem sobre o Programa Minha Casa, Minha Vida. 2012. 190 f. Dissertação (Mestrado em Economia) - Programa de Pós-Graduação em Economia, Universidade Federal de Santa Catarina, Florianópolis. 2012.

35 CARDOSO, Adauto Lúcio; JAENISCH, Samuel Thomas. Nova política, velhos desafios: problematizações sobre a implementação do programa Minha Casa Minha Vida na região metropolitana do Rio de Janeiro. Emetropolis: Revista eletrônica de Estudos Urbanos e Regionais, v. 5, p. 6-19, 2014.
} 
econômicos e políticos. Os processos violentos de reassentamento e a implantação das construções em periferias ou glebas menores, afastadas do tecido urbano, questões a serem desenvolvidas na próxima seção, explicitam com clareza a transformação do sentido sociocultural da moradia em tempos de financeirização.

Se o programa ao qual estamos nos referindo cria proprietários, Engels nunca se fez tão atual: para o filósofo, o problema da posse e sua desvalorização bem como a solução dada pela burguesia no que tange à moradia será sempre o título de propriedade ${ }^{36}$. Engels teorizou na Europa do século XIX, mas o pensamento é válido no Brasil do século XXI.

O PMCMV, lastreado por moradias deficitárias e não integradas aos fatores expressivos da cidade, não está preocupado em fomentar subprogramas de promoção da moradia pela moradia. Mais do que isso, "não resolve o déficit habitacional da população mais necessitada, haja vista que não existem políticas públicas de promoção de moradia pela moradia, ou mesmo financiamentos imobiliários feitos a um público sem renda"37.

A sistematização do programa enfraqueceu um ciclo progressista de debates acerca da política urbana e suas imbricações na política habitacional a partir de mobilizações da pauta constituinte. Discussões alavancadas pela criação do Ministério das Cidades, como a Reforma Urbana e a política do Programa Crédito Solidário $(2004)^{38}$, logo foram abafadas.

\section{A SEGREGAÇÃO SOCIOESPACIAL EM TEMPOS DE FINANCEIRIZAÇÃO: A LUTA DA POPULAÇÃO DE BAIXA RENDA PELA INTEGRAÇÃO AO TECIDO URBANO NO CONTEXTO DO PMCMV}

O Programa Minha Casa, Minha Vida abrange capitais, regiões metropolitanas e municípios com mais de 100 mil habitantes. Pode contemplar também municípios entre 50 e 100 mil habitantes com "população urbana superior ou igual a 70\%; a taxa de crescimento da

\footnotetext{
${ }^{36}$ ENGELS, Friedrich. Sobre a questão da moradia. Tradução de Nélio Schneider. São Paulo: Boitempo, 2015.

${ }^{37}$ MASTRODI, Josué; ZACCARA, Suzana Maria Loureiro Silveira. O que é o objeto "moradia" do Programa Minha Casa, Minha Vida? Revista de Direito da Cidade, Rio de Janeiro, vol. 8, n.3, p. 878, 2016.

38 O Crédito Solidário é um programa de financiamento habitacional com recursos do Fundo de Desenvolvimento Social - FDS, criado pelo Conselho Curador - CCFDS, conforme Resolução no 93/2004 e regulamentado pelo Ministério das Cidades.
} 
ISSN 1981-3694

(DOI): $10.5902 / 1981369431760$

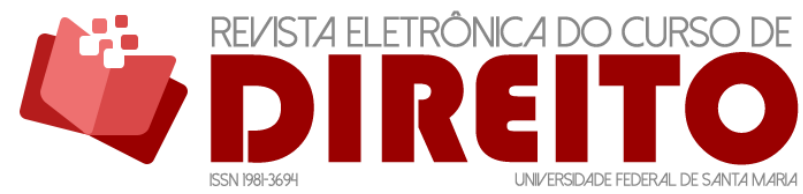

A MERCANTILIZAÇÃO DA MORADIA E O PROGRAMA MINHA CASA, MINHA VIDA: DAS RELAÇÕES ENTRE ESTADO E AGENTES PRIVADOS À SEGREGAÇÃO SOCIOESPACIAL

Clarissa de Oliveira Gomes MARQUeS da CUNHA ANNE GABRIELE ALVES GUIMARÃES

população superior a 5\% entre o período de 2007 a 2010 e taxa de crescimento populacional superior à taxa verificada no respectivo estado no período de 2000 a 2010"39.

No sentido aqui defendido, por meio deste programa, o Poder Público, na figura dos entes municipais, exerce papel secundário. O Estado, na figura da União, ainda que destine recursos ao pacote habitacional, dá ao mercado poder de decidir onde será realizado o empreendimento, a quem será destinado (faixa de renda) e quais as características das construções.

É o mercado quem decide também as pessoas jurídicas responsáveis pela incorporação. Coloca-se em pauta um direito social mercantilizado, refém dos interesses do mercado imobiliário e, consequentemente, do lucro.

O entendimento é de que, apesar de os direitos sociais, a exemplo da moradia, estarem dispostos em normas de caráter programático, o Estado precisa prestar positivamente estes direitos e garantias constitucionais. Observa-se, contudo, que o direito à habitação social de custo acessível vem sendo alijado diante da expansão do crédito e das finanças. No contexto do PMCMV, a moradia só é concedida se e quando o crédito do futuro morador for aprovado - quem não tem crédito dificilmente tem acesso às moradias, por mais que seja dito que este programa atenda pessoas sem renda ${ }^{40}$.

A apropriação urbana capitalista, portanto, afeta a promoção de moradias. Esta última, por outro lado, "não pode se dar de modo estanque da produção do espaço urbano" ${ }^{41}$. Planejar a cidade e prover habitação são projetos de inclusão social cuja execução deve acontecer de maneira integrada.

A implementação da moradia adequada está ligada à promoção do direito à cidade. Para isso, deve haver uma associação entre localização digna da casa e possibilidade coletiva de acesso aos recursos e vantagens oferecidas pela urbe.

O local urbano é composto de espaços onde todos devem ter ingerência e pelo qual consequentemente todos são responsáveis ${ }^{42}$. Ademais, o direito à moradia, sendo parte do

\footnotetext{
${ }^{39}$ MONTEIRO, Adriana Roseno; VERAS, Antonio Tolrino de Rezende. O Programa Minha Casa, Minha Vida e a produção do espaço urbano na cidade de Boa Vista - RR. Revista de Direito da Cidade, Rio de Janeiro, vol. 7, n.3, p. 1185, 2015.

${ }^{40}$ MASTRODI, Josué; ZACCARA, Suzana Maria Loureiro Silveira. O que é o objeto "moradia" do Programa Minha Casa, Minha Vida? Revista de Direito da Cidade, Rio de Janeiro, vol. 8, n.3, p. 859-885, 2016.

${ }^{41}$ MASTRODI, Josué; ZACCARA, Suzana Maria Loureiro Silveira. O que é o objeto "moradia" do Programa Minha Casa, Minha Vida? Revista de Direito da Cidade, Rio de Janeiro, vol. 8, n.3, p. 865, 2016.

42 KURTZ, Lahis Pasquali. A possível solução jurídica ao condomínio fechado: diálogo entre Direito das Coisas e Direito Urbanístico. Revista Eletrônica do Curso de Direito da UFSM, Santa Maria, RS, v. 8, n. 2, p. 293-310, dez. 2013. ISSN 1981-3694. Disponível em:
} 
direito à cidade, deve ser interpretado de forma ampla, considerando elementos como: habitabilidade, disponibilidade de serviços, infraestrutura e equipamentos públicos, localização adequada, adequação cultural, acessibilidade, segurança da posse e custo acessível. É crucial que as políticas, programas ou formas de produção da cidade enquanto espaço físico incluam tais aspectos ${ }^{43}$.

Por este motivo, o cumprimento do direito à moradia adequada precisa do reconhecimento pleno, por parte do Estado, de que este é um direito humano fundamental. A administração pública deve integrar plenamente o direito à moradia adequada ao planejamento urbano e às políticas habitacionais, em todos os níveis de governo.

Uma casa não é uma mercadoria - quatro paredes e um teto. É um lugar para viver com segurança, paz e dignidade, e um direito de todos os seres humanos ${ }^{44}$. A este respeito:

A questão de que tipo de cidade queremos não pode ser divorciada do tipo de laços sociais, relação com a natureza, estilos de vida, tecnologias e valores estéticos desejamos. 0 direito à cidade está muito longe da liberdade individual de acesso a recursos urbanos: é o direito de mudar a nós mesmos pela mudança da cidade. Além disso, é um direito comum antes de individual já que esta transformação depende inevitavelmente do exercício de um poder coletivo de moldar o processo de urbanização. A liberdade de construir e reconstruir a cidade e a nós mesmos é, como procuro argumentar, um dos mais preciosos e negligenciados direitos humanos ${ }^{45}$.

A noção de cidade é posta como a experimentação do tecido urbano, é pertencer àquele espaço de concretização de outros direitos fundamentais. Moradia digna, por sua vez, é a que se encontra em total adequação ao contexto urbano.

Feitas tais considerações, acredita-se que o programa de habitação aqui analisado fomentou o processo de ocupação excludente da cidade ${ }^{46}$. A política habitacional do PMCMV tem sido realizada pelos agentes de mercado em locais distantes da urbe. É justamente essa distância responsável por determinar a "terra barata".

https://periodicos.ufsm.br/revistadireito/article/view/9314/pdf. Acesso em: 16 fev. 2019. doi: http://dx.doi.org/10.5902/198136949314.

43 VANNUCHI, L.; IACOVINI, R.; PEREIRA, A.; MOREIRA, F. Inserção urbana no MCMV e a efetivação do direito à moradia adequada: uma avaliação de sete empreendimentos no estado de São Paulo. In: Anais do XVI ENANPUR - Espaço, Planejamento e Insurgências. Belo Horizonte, 2015.

${ }^{44}$ ROLNIK, Raquel. Direito à moradia. Resumo do pronunciamento efetuado na $63^{\mathrm{a}}$. Sessão da Assembleia Geral das Nações Unidas, em 23 de outubro de 2008, em Nova York. Traduzido do original em inglês por Emmanuel Cavalcante Porto, do IPEA/DIRUR.

45 HARVEY, David. O direito à cidade. Lutas Sociais, São Paulo, n.29, p.74, jul./dez. 2012.

${ }^{46} \mathrm{Fez}$-se uma análise exploratória e descritiva de artigos que se debruçaram sobre o Programa Minha Casa, Minha Vida nas regiões metropolitanas de São Paulo e Campinas, Rio de Janeiro e Boa Vista (RR). 
Os destinatários dos conjuntos habitacionais do MCMV tem casa própria, é fato, mas carecem de elementos capazes de fazê-los exercer efetivamente a moradia adequada e a cidade. Esclarecendo as contradições histórico-estruturais do referido programa:

O que é evidenciado a partir destes apontamentos é a segregação sócioespacial implícita na nova configuração espacial da cidade. Tal segregação deu-se não só pela condição de confinamento dos grupos sociais de baixa renda em loteamentos distantes do centro da cidade, que contavam com um precário serviço de transporte urbano e com dificuldades naturais de acesso pela falta da malha asfáltica. Figuravam também no rol de elementos geradores da segregação a escassez dos aparelhos públicos ${ }^{47}$.

O protagonismo do mercado privado propiciou a criação de conjuntos habitacionais extensos, localizados em áreas menos valorizadas, cujo preço da terra é barato. Percebe-se que isto é "uma condição fundamental para a rentabilidade das operações, reiterando um padrão histórico de ocupação do território onde o assentamento da população pobre é feito prioritariamente em periferias precárias e mal equipadas" ${ }^{48}$. Constata-se, portanto, que o MCMV vem exercendo, nas localidades pesquisadas, um papel ativo na perpetuação da segregação em razão da renda e na reiteração da periferia enquanto lugar dos desvalidos nas cidades brasileiras.

A despeito da verificação de certa diferença de padrão periférico atual comparado a períodos passados, já se consegue identificar nesta "política habitacional" um vetor reprodutivo da exclusão socioespacial. Sob a ótica capitalista, entretanto, isto acaba sendo uma consequência do modelo que determinou a formulação do programa, imbricado por caracteres que condicionam a moradia aos interesses mercadológicos.

O lucro é tão relevante que fatores como qualidade do projeto e atributos urbanísticos nos arredores dos empreendimentos não exercem qualquer influência positiva sobre a taxa de retorno das construtoras. Os megaempreendimentos são estimulados porque possibilitam ganhos de escala significativos. Já os terrenos devem ser distantes o bastante para minimizar a porcentagem de investimentos.

Sob a perspectiva da financeirização da terra, a estrutura pensada para o MCMV não expressa a busca pela integração ao solo urbano das populações de baixa renda, mas ratifica a

\footnotetext{
${ }^{47}$ ROSA, Marta Ferreira. Segregação Socioespacial na Política Urbana: Contradições histórico-estruturais no Programa Minha Casa, Minha Vida. 2015. 142 f. Dissertação (Mestrado em Política Social) - Programa de Pós-Graduação em Política Social, Universidade de Brasília, Brasília. 2015, p. 96.

48 ROLNIK, Raquel et al. O Programa Minha Casa Minha Vida nas regiões metropolitanas de São Paulo e Campinas: aspectos socioespaciais e segregação. Cadernos Metrópole, São Paulo, v. 17, n. 33, p. 128, maio 2015.
} 
marginalização dos vulneráveis. Não há nenhuma preocupação em situar as unidades habitacionais em espaços dentro da malha urbana, mas às margens. Colocar moradias dignas disponíveis, favorecidas pelo acesso aos serviços públicos, exige dois fatores a serem superados, terra urbanizada e financiamento ${ }^{49}$. 0 setor imobiliário não tem interesse nessa superação, tendo em vista não decorrer dela maximização de lucros.

Sobre a regulação urbanística no Brasil e os desafios existentes para além do PMCMV:

O quadro de contraposição entre uma minoria qualificada e uma maioria com condições urbanísticas precárias relaciona-se a todas as formas de injustiça social. Essa situação de exclusão é muito mais do que a expressão da desigualdade de renda e das desigualdades sociais: ela é agente de reprodução dessa desigualdade. Em uma cidade dividida entre a porção legal, rica e com infraestrutura e a ilegal, pobre e precária, a população que está em situação desfavorável acaba tendo muito pouco acesso a oportunidades de trabalho, cultura ou lazer. Simetricamente, as oportunidades de crescimento circulam nos meios daqueles que já vivem melhor, pois a sobreposição das diversas dimensões da exclusão incidindo sobre a mesma população fazem com que a permeabilidade entre as duas partes seja cada vez menor. Do ponto de vista espacial, essa progressiva separação entre as partes ricas e pobres da cidade potencializa ainda mais as tensões [...] fragmentando e cerceando ainda mais o espaço urbano ${ }^{50}$.

Aqui cabe destacar a experiência nefasta da insegurança da posse ${ }^{51}$, questão de economia política por meio da qual o bloqueio à terra urbanizada incide principalmente sobre os moradores de menor renda.

Nestes jogos de poder e de mal-estares (in)visibilizados, as grandes corporações e os capitais financeiros aumentam gradativamente sua capacidade de impor políticas públicas. Uma razão muito importante, que explica a grave crise do capitalismo, é a perda da capacidade regulatória do sistema.

A globalização neoliberal criou novas condições para que os ativos possam se deslocar livremente. Inclusive, a capacidade de regulação dos Estados está em declínio. A tão ansiada

\footnotetext{
49 MARICATO, Ermínia. Metrópole, Legislação e Desigualdade. Estudos Avançados, São Paulo, n. 17 (48), 2003, p. 151-167.

${ }^{50}$ ROLNIK, Raquel; CYMBALISTA, Renato. Regulação urbanística no Brasil: conquistas e desafios de um modelo em construção. In: Anais do Seminário Internacional: Gestão da Terra Urbana e Habitação de Interesse Social, PUCCAMP, 2000. p. 2-3.

51 ROLNIK, Raquel. Guerra dos lugares: a colonização da terra e da moradia na era das finanças. São Paulo: Boitempo, 2015, p. 151-152.
} 
utopia do mercado total torna-se um problema quando não se dispõe de instrumentos para equilibrar os inevitáveis excessos ${ }^{52}$.

A lógica da urbanização corporativa e da cidade corporativa é explicada por Milton Santos. É também este geógrafo que acredita no fomento à produção de espaços vazios dentro das cidades pelo Poder Público. E continua:

O próprio poder público torna-se criador privilegiado de escassez [...] incapaz de resolver o problema da habitação, empurra a maioria da população para as periferias; e empobrece ainda mais os mais pobres, forçados a pagar caro pelos precários transportes coletivos e a comprar caro bens de um consumo indispensável e serviços essenciais que o poder público não é capaz de oferecer. 0 poder público, entretanto, não age apenas de forma indireta. Ele também atua de forma direta na geração de problemas urbanos, ainda que prometendo resolvê-los ${ }^{53}$.

No contexto do PMCMV, a urbanização corporativa se impõe através de um processo contraditório que confronta cidade, grupos familiares, modos de produção urbana, formas de vida e comportamentos. Esta política habitacional funciona, a nosso ver, como um pretexto para o mercado funcionar e gerar lucro, sendo um meio de legitimar a financeirização da moradia no Brasil e perpetuar o "lugar dos pobres", oriundo, sobretudo, do intenso crescimento econômico aliado ao processo de urbanização com aumento da desigualdade ${ }^{54}$.

$\mathrm{Na}$ era das finanças, não só a moradia, mas a cidade perde sentido, transformando-se em uma facilitadora da mercantilização das relações e em uma máquina de reprodução de modos de vida dominantes, coloniais, modernos e neoliberais.

\section{CONCLUSÃO}

A moradia constitui a mais nova fronteira de expansão do capital financeiro. A partir da mercantilização, existe a crença de que os mercados são capazes de regular a alocação da terra.

\footnotetext{
52 LANDER, Edgardo. Com o tempo contado: crise civilizatória, limites do planeta, ataques à democracia e povos em resistência. In: LANG, Miriam et al. (Org.). Descolonizar o imaginário. Debates sobre pósextrativismo e alternativas ao desenvolvimento. São Paulo: Elefante, 2016, p. 215-253.

53 SANTOS, Milton. A urbanização brasileira. São Paulo: Hucitec, 1993, p. 111.

${ }^{54}$ KURTZ, Lahis Pasquali. A possível solução jurídica ao condomínio fechado: diálogo entre Direito das Coisas e Direito Urbanístico. Revista Eletrônica do Curso de Direito da UFSM, Santa Maria, RS, v. 8, n. 2, p. 293-310, dez. 2013. ISSN 1981-3694. Disponível em: https://periodicos.ufsm.br/revistadireito/article/view/9314/pdf. Acesso em: 16 fev. 2019. doi: http://dx.doi.org/10.5902/198136949314.
} 
ISSN 1981-3694

(DOI): 10.5902/1981369431760

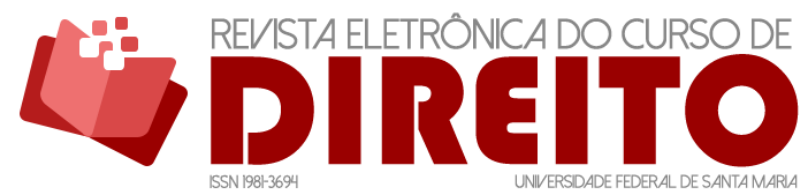

A MERCANTILIZAC̄̃̃ DA MORADIA E O PROGRAMA MINHA CASA, MINHA VIDA: DAS RELAÇÕES ENTRE ESTADO E AGENTES PRIVADOS À SEGREGAÇÃO SOCIOESPACIAL

Clarissa de OliveIRA GOMES MARQUES DA CUNHA ANNE GABRIELE ALVES GUIMARÃES

É justamente o financiamento do espaço construído que ocasiona o abandono do conceito de moradia enquanto bem social.

As políticas públicas desconstroem a habitação como um meio de distribuição de riqueza, tornando-a um meio de acesso à riqueza. A extração de renda e a acumulação de recursos prevalecem, portanto, sobre a implementação da moradia de custo acessível em condições adequadas. O Estado renuncia ao seu papel de provedor deste direito e atua como um mero facilitador, transferindo para o mercado o poder de decidir sobre o que construir e onde construir. Para o mercado só importa o lucro, por isso escolhem áreas afastadas, onde o preço dos terrenos é mais barato.

A mercantilização da moradia, típica da dinâmica neoliberal, está representada no Brasil pelo Programa Minha Casa, Minha Vida, programa federal vigente. Lançado em 2009, todos os critérios de decisão sobre localização dos projetos imobiliários estão nas mãos dos agentes privados. O processo de produção da “casa própria” é baseado na padronização e no menor custo possível.

O resultado da atuação do mercado, através da permissão promíscua do Estado, é a construção de megaempreendimentos padronizados inseridos em lugares sem acesso ao transporte público, lazer e outros elementos que constituem o direito à cidade. As localizações afastadas significam terreno barato. Não existe uma política pública preocupada com a moradia digna. Ao contrário, se o que importa é a rentabilidade das empresas, a solução viável é edificar em áreas sem infraestrutura adequada, sem espaços comerciais e em condições inadequadas de mobilidade.

O PMCMV confunde o direito à moradia com a propriedade, ou melhor, com o título de proprietário. Ignora a cidade, nesta perspectiva, enquanto espaço de realizações coletivas e acaba ratificando a segregação socioespacial dos mais vulneráveis.

Em tempos de urbanização acelerada, que necessita do excedente produtivo para se reciclar, os processos de incorporação imobiliária e especulação definem a produção capitalista da urbe. Os subsídios públicos, na verdade, não fomentam a moradia acessível, mas sim o crédito.

Não adianta o título de propriedade quando persiste a configuração da geografia da pobreza, definindo o "lugar dos pobres" na cidade. A moradia adequada vai além do teto fornecido pelo PMCMV. Mais ainda, não deve ser refém dos nexos entre mercados nem do setor financeiro. Se o cerne dos conflitos urbanos está relacionado a tal forma de produção 
habitacional, é porque nossos sistemas econômico e político são incapazes de oferecer abrigo decente para além dos circuitos globalizados do capitalismo financeiro.

\section{REFERÊNCIAS}

ARAGÃO, Thêmis Amorim. A financeirização da moradia no Brasil: a cidade como direito ou mercadoria? Le Monde Diplomatique. Brasil, web, 26 ago. 2016.

BRAND, Ulrich. Estado e políticas públicas: sobre os processos de transformação. In: LANG, Miriam et al. (Org.). Descolonizar o imaginário. Debates sobre pós-extrativismo e alternativas ao desenvolvimento. São Paulo: Elefante, 2016, p. 123-137.

CARDOSO, Adauto Lúcio; JAENISCH, Samuel Thomas. Nova política, velhos desafios: problematizações sobre a implementação do programa Minha Casa Minha Vida na região metropolitana do Rio de Janeiro. E-metropolis: Revista eletrônica de Estudos Urbanos e Regionais, v. 5, p. 6-19, 2014.

CHOMSKY, Noam. O lucro ou as pessoas: neoliberalismo e ordem global. Trad. Pedro Jorgensen Jr. Rio de Janeiro: Bertrand Brasil, 2002.

CORRÊA, Geovana de Medeiros. A habitação social em foco: uma abordagem sobre o Programa Minha Casa, Minha Vida. 2012. 190 f. Dissertação (Mestrado em Economia) - Programa de PósGraduação em Economia, Universidade Federal de Santa Catarina, Florianópolis. 2012.

CUNHA, Clarissa de Oliveira Gomes Marques da; PORTO, Simone Peixoto Ferreira. A negação da natureza e o projeto de desenvolvimento: a busca por uma racionalidade ambientalmente sustentável. Revista Eletrônica do Curso de Direito da UFSM, Santa Maria, RS, v. 12, n. 3, p. 910-936, dez. 2017. ISSN 1981-3694. Disponível em:

https://periodicos.ufsm.br/revistadireito/article/view/27173. Acesso em: 15 fev. 2019. doi: http://dx.doi.org/10.5902/1981369427173.

ENGELS, Friedrich. Sobre a questão da moradia. Tradução de Nélio Schneider. São Paulo: Boitempo, 2015.

HARVEY, David. O direito à cidade. Lutas Sociais, São Paulo, n.29, p.73-89, jul./dez. 2012.

HARVEY, David. Cidades rebeldes: do direito à cidade à revolução urbana. São Paulo: Martins Fontes, 2014.

KURTZ, Lahis Pasquali. A possível solução jurídica ao condomínio fechado: diálogo entre Direito das Coisas e Direito Urbanístico. Revista Eletrônica do Curso de Direito da UFSM, Santa Maria, RS, v. 8, n. 2, p. 293-310, dez. 2013. ISSN 1981-3694. Disponível em:

https://periodicos.ufsm.br/revistadireito/article/view/9314/pdf. Acesso em: 16 fev. 2019. doi: http://dx.doi.org/10.5902/198136949314. 
LANDER, Edgardo. Com o tempo contado: crise civilizatória, limites do planeta, ataques à democracia e povos em resistência. In: LANG, Miriam et al. (Org.). Descolonizar o imaginário. Debates sobre pós-extrativismo e alternativas ao desenvolvimento. São Paulo: Elefante, 2016, p. 215-253.

MARICATO, Ermínia. Metrópole, Legislação e Desigualdade. Estudos Avançados, São Paulo, n. 17 (48), 2003, p. 151-167.

MASTRODI, Josué; ZACCARA, Suzana Maria Loureiro Silveira. O que é o objeto "moradia" do Programa Minha Casa, Minha Vida? Revista de Direito da Cidade, Rio de Janeiro, vol. 8, n.3, p.859-885, 2016.

MONTEIRO, Adriana Roseno; VERAS, Antonio Tolrino de Rezende. O Programa Minha Casa, Minha Vida e a produção do espaço urbano na cidade de Boa Vista - RR. Revista de Direito da Cidade, Rio de Janeiro, vol. 7, n.3, p.1180-1199, 2015.

NUNES DE SOUZA, Sérgio Iglesias. Direito à moradia e de habitação: análise comparativa e seu aspecto teórico e prático com os direitos da personalidade. 3. ed. São Paulo: Thomson Reuters Revista dos Tribunais, 2013.

ROLNIK, Raquel; CYMBALISTA, Renato. Regulação urbanística no Brasil: conquistas e desafios de um modelo em construção. In: Anais do Seminário Internacional: Gestão da Terra Urbana e Habitação de Interesse Social, PUCCAMP, 2000.

ROLNIK, Raquel et al. O Programa Minha Casa Minha Vida nas regiões metropolitanas de São Paulo e Campinas: aspectos socioespaciais e segregação. Cadernos Metrópole, São Paulo, v. 17, n. 33, p. 127-154, maio 2015.

ROLNIK, Raquel. O que é cidade? São Paulo: Brasiliense, 1995.

ROLNIK, Raquel. Guerra dos lugares: a colonização da terra e da moradia na era das finanças. São Paulo: Boitempo, 2015.

ROLNIK, Raquel. Direito à moradia. Resumo do pronunciamento efetuado na $63^{\mathrm{a}}$. Sessão da Assembleia Geral das Nações Unidas, em 23 de outubro de 2008, em Nova York. Traduzido do original em inglês por Emmanuel Cavalcante Porto, do IPEA/DIRUR.

ROSA, Marta Ferreira. Segregação Socioespacial na Política Urbana: Contradições históricoestruturais no Programa Minha Casa, Minha Vida. 2015. 142 f. Dissertação (Mestrado em Política Social) - Programa de Pós-Graduação em Política Social, Universidade de Brasília, Brasília. 2015.

ROYER, Luciana de O. Financeirização da política habitacional: limites e perspectivas. 2009. 193 f. Tese (Doutorado em Arquitetura e Urbanismo) - Programa de Pós-Graduação em Arquitetura e Urbanismo, Universidade de São Paulo, São Paulo. 2009.

SHIMBO, Lúcia Zanin. Habitação social, habitação de mercado: a confluência entre estado, empresas construtoras e capital financeiro. 2010. $361 \mathrm{f}$. Tese (Doutorado em Arquitetura e Urbanismo) - Programa de Pós-Graduação em Arquitetura e Urbanismo, Escola de Engenharia de São Carlos da Universidade de São Paulo, São Paulo. 2010. 
A MERCANTILIZACC̃̃O DA MORADIA E O PROGRAMA MINHA CASA, MINHA VIDA: DAS RELAÇÕES ENTRE ESTADO E AGENTES PRIVADOS À SEGREGAÇÃO SOCIOESPACIAL

Clarissa de Oliveira Gomes MARQUes da CUNHA ANNE GABRIELE ALVES GUIMARÃES

SANTOS, Milton. A urbanização brasileira. São Paulo: Hucitec, 1993.

VANNUCHI, L.; IACOVINI, R.; PEREIRA, A.; MOREIRA, F. Inserção urbana no MCMV e a efetivação do direito à moradia adequada: uma avaliação de sete empreendimentos no estado de São Paulo. In: Anais do XVI ENANPUR - Espaço, Planejamento e Insurgências. Belo Horizonte, 2015.

Recebido em: 07.05.2018 / Revisões requeridas em: 06.02.2019 / Aprovado em: 21.06.2019 / Publicado em: 20.07.2019

\section{COMO FAZER REFERÊNCIA AO ARTIGO (ABNT):}

CUNHA, Clarissa de Oliveira Gomes Marques da; GUIMARÃES, Anne Gabriele Alves. A mercantilização da moradia e o Programa Minha Casa, Minha Vida: das relações entre estado e agentes privados à segregação socioespacial.

Revista Eletrônica do Curso de Direito da UFSM, Santa Maria, RS, v. 14, n. 3, e31760, set./dez. 2019. ISSN 19813694. DOI: http://dx.doi.org/10.5902/1981369431760. Disponível em:

https://periodicos.ufsm.br/revistadireito/article/view/31760 Acesso em: dia mês. ano.

Direitos autorais 2019 Revista Eletrônica do Curso de Direito da UFSM

Editores responsáveis: Rafael Santos de Oliveira e Angela Araujo da Silveira Espindola

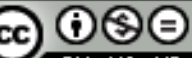

Esta obra está licenciada com uma Licença Creative Commons Atribuição-NãoComercial-SemDerivações 4.0 Internacional.

\section{SOBRE AS AUTORAS}

\section{Clarissa de Oliveira Gomes Marques da Cunha}

Pós-Doutorado na The New School of Social Research - NY (Bolsista CAPES), Doutora em Direito pela Universidade Federal de Pernambuco (2012), Estágio de Doutorado realizado na Universidade de Paris (Bolsista PDEE/CAPES), Professora da Universidade de Pernambuco (UPE) e do Programa de Pós-Graduação em Direito da Faculdade Damas (PPGD-ARIC-FADIC), Coordenadora do Grupo de Pesquisa e Estudos Transdisciplinares sobre Meio Ambiente, Diversidade e Sociedade - GEPT/UPE (Responsável pela Pesquisa "Meio Ambiente e Tutela Jurídica da Memória Afro-indígena: antes que a ancestralidade torne-se apenas uma lembrança" CNPq-UPE e "Fundamentos da Modernidade Periférica: da legitimidade de ser negro à praxes cidadã de educação e reconhecimento ancestral no sertão de Pernambuco" CNPq-UPE), Coordenadora do Coletivo Direitos em Movimento - DIMO (Projeto de Extensão - UPE), Pesquisadora-colaboradora do Projeto TransVERgente (UPE/FIOCRUZ), Pesquisadora do Grupo de Pesquisa Historiografias Descoloniais: direito, natureza e coletividades na América Latina. Consultora ambiental e advogada. Tem experiência na área de Direito, com ênfase em Meio Ambiente, atuando principalmente nos seguintes temas: pensamento decolonial, identidade cultural e comunidades tradicionais.

\section{ANNE GABRIELE ALVES GUIMARÃES}

Graduada em Direito - Universidade de Pernambuco/campus Arcoverde. Pesquisadora dos seguintes grupos de pesquisa: Grupo de Estudos e Pesquisas Transdisciplinares sobre Meio Ambiente, Diversidade e Sociedade (UPE/CNPq), Fundamentos do Direito Civil Contemporâneo (UPE/CNPq) e Direito do Trabalho e dilemas da sociedade contemporânea (UPE/CNPq). Integrante do Projeto de Extensão Coletivo Direitos em Movimento (DIMO/UPE) e pesquisadora-colaboradora no Projeto Direito à saúde: ressonâncias da Transposição do Rio São Francisco (UPE/Fiocruz). Possui interesses nas áreas de: Direito Ambiental, Direitos Humanos, Gênero e Interdisciplinaridade. 